ISSN 1112-9867

http://www.jfas.info

\title{
REMOVAL OF METHYLENE BLUE FROM AQUEOUS SOLUTIONS USING ALUM SLUDGE: SORPTION OPTIMIZATION BY RESPONSE SURFACE METHODOLOGY
}

\author{
S. M. Yusuff*, K. K. Ong, W. M. Z W. Yunus, A. Fitrianto and M. B. Ahmad \\ Department of Defence Science, Faculty of Defence Science and Technology, \\ UniversitiPertahananNasional Malaysia, Sungai Besi Camp, 57000 Kuala Lumpur, Malaysia
}

Published online: 10 September 2017

\begin{abstract}
A sorption process on low cost sorbents is one the promising methods for removing of these pollutants from aqueous solutions. This report describes use of drinking water treatment sludge which is abundantly available from drinking water treatment plants, to remove methylene blue (MB) dye from aqueous solutions. The main objective of this work is to determine the optimum conditions for removal of $\mathrm{MB}$ dye, a common compound that is used as a model for organic chemicals. Response surface methodology (RSM) is used in the optimization of the sorption process. Six independent important factors which are temperature of treatment, $\mathrm{pH}$ of solution, dosage of sorbent, initial dye concentration, contact period and temperature of sorption were investigated using batch sorption technique with a 26 half factorial faced centered central composite design.
\end{abstract}

Keywords: drinking water sludge; methylene blue; response surface methodology.

Author Correspondence, e-mail: sol_ea@yahoo.com

doi: $\underline{\text { http://dx.doi.org/10.4314/jfas.v9i3s.41 }}$

\section{INTRODUCTION}

Industrial effluents which contain various organic and inorganic pollutants contribute mainly to environmental pollution problem [1]. Synthetic dye is one of the organic chemicals which is widely used in various industries such as textile, cosmetics, pharmaceutical [2], paper, printing and food industries [3]. Consequently, the discharge of the synthetic dyes into 
hydrosphere cause significant pollution [4]. Consuming water contaminated by synthetic dye such methylene blue (MB) will seriously affect human cardiovascular, gastrointestinal, central nervous system [5-6] hematologic, dermatologic and genitourinary. Hence, the treatment of dye effluents before discharged to the water bodies is highly important $[5,7]$.

Adsorption process is the most widely method used to remove dyes [8-9] due to its ease of application and cost effectiveness [10]. In addition, the adsorption process has no side product and the adsorbent can be regenerated and reused as well [6]. The cost-effective waste materials that have been employed as dye adsorbents including Ephedra strobilacea sawdust, wastewater sludge [3] and sewage sludge [11]. The removal of MB dye onto various adsorbents were due to the formation of physical and chemical bonds including van der Waals forces, hydrogen bonding, and hydrophobic interactions [10] between adsorbent and MB molecules.

This report describes the results of our study on the potential of drinking water treatment sludge which is abundantly available from drinking water treatment plants, to remove $\mathrm{MB}$ from aqueous solutions. Six independent important factors which are temperature of treatment, $\mathrm{pH}$ of solution, dosage of sorbent, initial dye concentration, contact period and temperature of sorption were investigated using batch sorption technique with a $2^{6}$ half factorial faced centred central composite design. A $2^{6}$ half factorial faced centred central composite design was employed to investigate the effects of temperature of treatment, $\mathrm{pH}$ of solution, dosage of sorbent, initial dye concentration, contact period and temperature of sorption at laboratory scale. In order to determine the optimum conditions of the sorption process, response surface methodology (RSM) was applied.

\section{METHODOLOGY}

\subsection{Preparation of Sorbent}

The sorbents were prepared from a fresh drinking water treatment sludge cake which was obtained from a local waste water treatment plant. The dried alum sludge (labelled as T100) was obtained by drying the collected sludge in an oven at $105^{\circ} \mathrm{C}$ for an overnight. The thermally treated sludge sorbents were prepared by heating the dried sludge in a furnace at a heating temperature of 450 (labelled as T450) or 800 (labelled as T800) ${ }^{\circ} \mathrm{C}$ for $7 \mathrm{hr}$. The heated sludge samples were cooled to room temperature, sieved to obtain particle sizes of 100 to $150 \mu \mathrm{m}$ and stored in polyethylene bottles with screwed caps. 


\subsection{Preparation of Methylene Blue Solutions (Sorbates)}

Methylene blue (MB) dye supplied by Sigma Aldrich (United Kingdom) was used as a sorbate. A stock solution of $\mathrm{MB}$ dye solution $(1000 \mathrm{mg} / \mathrm{L})$ was prepared by dissolving $0.5 \mathrm{~g}$ of the dye powder into distilled water in a $500 \mathrm{~mL}$ of volumetric flask. Then, the stock solution was diluted with distilled water to obtain the desired MB dye concentrations (Table 1) to prepare various MB working solutions. The initial $\mathrm{pHs}$ of the solutions were adjusted to the desired values by adding $0.1 \mathrm{M} \mathrm{NaOH}$ or $0.2 \mathrm{M} \mathrm{HCl}$ solutions.

\subsection{Experimental Design}

Six process parameters, i.e. temperature of treatment, $\mathrm{pH}$ of solution, dosage of sorbent, initial MB dye concentration, contact period and temperature of sorption were used as the independent factors and the percentage removal of MB dye as the dependent response. Table 1 shows the independent factors, experimental range and levels used in the batch sorption experiments of MB dye removal with the total of 49 experiments conducted at $\alpha=1$ using a $2^{6}$ half factorial faced centered central composite design with five replicates at the center point and twelve experiments at axial point.

\subsection{Batch Sorption Experiments}

The sorption experiments were conducted by shaking the required amounts of sorbents into 20 $\mathrm{mL}$ of $\mathrm{MB}$ aqueous working solutions in $250 \mathrm{~mL}$ Erlenmeyer flasks and agitated at $180 \mathrm{rpm}$ in a water bath at chosen temperature and contact period. The solutions were filtered using filter paper (Whatman, grade 3) and their final concentrations were analysed using UV-vis Spectrophotometer (Thermo Scientific, Genesys 6) at the wavelength of $665 \mathrm{~nm}$. The percentage removal of MB dye was taken as a response $(R)$ in this study and calculated as:

$R=\left(\frac{C_{i}-C_{f}}{C_{i}}\right) * 100$

where, $C_{i}$ and $C_{f}$ are the initial and final MB dye concentrations $(\mathrm{mg} / \mathrm{L})$ of the solutions respectively.

\subsection{Statistical Analysis}

The experimental data were subjected to a second order polynomial regression analysis using MINITAB 16 software to analyse the experimental data by estimating the response as the function of independent variables. The general form of the second order polynomial regression model used to explain MB dye removal (Equation (2)).

$\hat{R}=\beta_{0}+\sum \beta_{i} X_{i}+\sum \beta_{i j} X_{i} X_{J}+\sum \beta_{i i} X_{i}^{2}$

where $\hat{R}$ is the predicted response (MB dye removal), $\beta_{0}$ is the intercept, $\beta_{i}$ is effects of 
the linear terms, $\beta_{i i}$ is effects of the quadratic terms, $\beta_{i j}$ is effects of the interaction terms and $X_{i}$ are coded value of the corresponding $i^{\text {th }}$ factors. The analysis of variance (ANOVA) with F-value, the lack of fit test $(L O F)$ and the coefficient of determination, $\mathrm{R}^{2}$ were used to determine the appropriate model. The optimum conditions for the removal was predicted using 'response optimizer'. The response contour plot was used to present the interaction effects of the significant variables.

\section{RESULTS AND DISCUSSION}

\subsection{Development of Regression Model Equation for MB Removal}

Table 1 and 2 show the experimental design matrix, the actual and predicted dye removal efficiencies respectively. The predicted values were calculated from RSM while the actual values are measured from the experiment. The estimated optimum settings of each variable for removal of $\mathrm{MB}$ dye (\%) and the interaction effects among the variables were analysed using the FCCCD method. The maximum removal efficiency of dye was found to be $100 \%$. The second order polynomial equation fitted between the responses represent colour removal efficiency $(R)$ and the input variable of temperature of treatment $\left(X_{1}\right), \mathrm{pH}$ of solution $\left(X_{2}\right)$, dosage of sorbent $\left(X_{3}\right)$, contact period $\left(X_{4}\right)$, initial dye concentration $\left(X_{5}\right)$ and temperature of sorption $\left(X_{6}\right)$ is expressed in Equation (3) after the insignificant terms (P-value $\left.>0.05\right)$ were eliminated.

$$
\begin{aligned}
\hat{R}=99.923+ & 17.8933 X_{3}+0.0777 X_{4}-0.2138 X_{5}-0.036 X_{6}-7.1018 X_{3} X_{3}-0.028 X_{3} X_{4} \\
+ & 0.093 X_{3} X_{5}+0.067 X_{3} X_{6}-0.001 X_{5} X_{6}(3)
\end{aligned}
$$

where $\hat{R}$ represents the predicted response (MB dye removal) while $X_{1}, X_{2}, X_{3}, X_{4}, X_{5}$ and $X_{6}$ are the coded values of the six independent variables.

Table 1.Central composite design matrix

\begin{tabular}{cccccc}
\hline Independent factor & Symbol & Unit & Low (-1) & Centre (0) & High (+1) \\
\hline Temperature of treatment, $\mathrm{X}_{1}$ & Temp. Heat. & ${ }^{\circ}$ & 100 & 450 & 800 \\
pH of solution, $\mathrm{X}_{2}$ & $\mathrm{pH}$ & $\mathrm{pH}$ & 2 & 6 & 10 \\
Dosage of sorbent, $\mathrm{X}_{3}$ & $\mathrm{~W}$ & $\mathrm{~g}$ & 0.1 & 1.55 & 3.0 \\
Contact period, $\mathrm{X}_{4}$ & Time & $\mathrm{min}$ & 60 & 120 & 180 \\
Initial dye concentration, $\mathrm{X}_{5}$ & Conc. & $\mathrm{mg} / \mathrm{L}$ & 50 & 150 & 250 \\
Temperature of sorption, $\mathrm{X}_{6}$ & Temp. Sorp. & ${ }^{\circ} \mathrm{C}$ & 25 & 52.5 & 80 \\
\hline
\end{tabular}


Table 2. Experimental and predicted values

\begin{tabular}{|c|c|c|c|c|c|c|c|c|}
\hline Run & Temp. Heat & pH & Weight & Time & Conc. & Temp. Sorp. & $\mathbf{R}$ & $\widehat{\mathbf{R}}$ \\
\hline 1 & 100 & 10 & 3 & 180 & 50 & 80 & 99.5 & 100 \\
\hline 2 & 800 & 10 & 0.1 & 180 & 250 & 25 & 73.3 & 57.0 \\
\hline 3 & 800 & 2 & 3 & 60 & 50 & 25 & 99.8 & 95.4 \\
\hline 4 & 450 & 6 & 0.1 & 120 & 150 & 52.5 & 73.3 & 70.5 \\
\hline 5 & 100 & 2 & 3 & 180 & 250 & 80 & 99.9 & 98.0 \\
\hline 6 & 450 & 6 & 1.55 & 120 & 150 & 52.5 & 100 & 99.9 \\
\hline 7 & 100 & 10 & 3 & 60 & 250 & 80 & 99.9 & 98.8 \\
\hline 8 & 100 & 10 & 0.1 & 180 & 250 & 80 & 43.2 & 41.7 \\
\hline 9 & 100 & 2 & 3 & 60 & 50 & 80 & 100 & 100 \\
\hline 10 & 450 & 10 & 1.55 & 120 & 150 & 52.5 & 99.9 & 99.9 \\
\hline 11 & 100 & 2 & 3 & 180 & 50 & 25 & 99.8 & 94.5 \\
\hline 12 & 450 & 6 & 1.55 & 120 & 150 & 52.5 & 100 & 99.9 \\
\hline 13 & 100 & 2 & 0.1 & 180 & 250 & 25 & 55.0 & 57.0 \\
\hline 14 & 100 & 2 & 0.1 & 180 & 50 & 80 & 99.0 & 98.5 \\
\hline 15 & 100 & 10 & 0.1 & 180 & 50 & 25 & 99.3 & 100 \\
\hline 16 & 800 & 10 & 0.1 & 60 & 250 & 80 & 39.2 & 32.7 \\
\hline 17 & 450 & 6 & 1.55 & 120 & 250 & 52.5 & 99.9 & 87.7 \\
\hline 18 & 100 & 2 & 0.1 & 60 & 250 & 80 & 13.8 & 32.7 \\
\hline 19 & 800 & 2 & 0.1 & 60 & 50 & 80 & 90.3 & 89.5 \\
\hline 20 & 800 & 2 & 0.1 & 180 & 50 & 25 & 92.9 & 100 \\
\hline 21 & 450 & 6 & 1.55 & 120 & 150 & 52.5 & 100 & 99.9 \\
\hline 22 & 450 & 2 & 1.55 & 120 & 150 & 52.5 & 99.9 & 99.9 \\
\hline 23 & 450 & 6 & 1.55 & 120 & 150 & 25 & 99.9 & 100 \\
\hline 24 & 800 & 10 & 3 & 180 & 50 & 25 & 94.3 & 94.5 \\
\hline 25 & 100 & 10 & 3 & 180 & 250 & 25 & 99.9 & 100 \\
\hline 26 & 450 & 6 & 1.55 & 120 & 150 & 80 & 100 & 97.7 \\
\hline 27 & 450 & 6 & 1.55 & 120 & 150 & 52.5 & 99.9 & 99.9 \\
\hline 28 & 800 & 2 & 3 & 180 & 50 & 80 & 99.8 & 100 \\
\hline 29 & 100 & 2 & 3 & 60 & 250 & 25 & 100 & 100 \\
\hline 30 & 450 & 6 & 1.55 & 60 & 150 & 52.5 & 100 & 97.9 \\
\hline 31 & 100 & 10 & 0.1 & 60 & 50 & 80 & 99.8 & 89.5 \\
\hline
\end{tabular}




\begin{tabular}{ccccccccc}
\hline 32 & 450 & 6 & 3 & 120 & 150 & 52.5 & 99.9 & 99.4 \\
33 & 800 & 10 & 0.1 & 180 & 50 & 8 & 98.8 & 98.5 \\
34 & 800 & 2 & 3 & 180 & 250 & 25 & 99.9 & 100 \\
35 & 450 & 6 & 1.55 & 180 & 150 & 52.5 & 100 & 100 \\
36 & 800 & 10 & 3 & 180 & 250 & 80 & 99.9 & 98.0 \\
37 & 100 & 6 & 1.55 & 120 & 150 & 52.5 & 100 & 99.9 \\
38 & 450 & 6 & 1.55 & 120 & 150 & 52.5 & 99.9 & 99.9 \\
39 & 800 & 10 & 0.1 & 60 & 50 & 25 & 99.5 & 93.9 \\
40 & 100 & 10 & 0.1 & 60 & 250 & 25 & 48.9 & 48.0 \\
41 & 800 & 2 & 3 & 60 & 250 & 80 & 99.9 & 98.8 \\
42 & 800 & 10 & 3 & 60 & 50 & 80 & 98.5 & 100 \\
43 & 800 & 2 & 0.1 & 180 & 250 & 80 & 38.5 & 41.7 \\
44 & 100 & 10 & 3 & 60 & 50 & 25 & 99.5 & 95.4 \\
45 & 800 & 10 & 3 & 60 & 250 & 25 & 99.9 & 100 \\
46 & 100 & 2 & 0.1 & 60 & 50 & 25 & 95.0 & 93.9 \\
47 & 450 & 6 & 1.55 & 120 & 50 & 52.5 & 99.7 & 100 \\
48 & 800 & 6 & 1.55 & 120 & 150 & 52.5 & 99.8 & 99.9 \\
49 & 800 & 2 & 0.1 & 60 & 250 & 25 & 39.6 & 48.0 \\
\hline
\end{tabular}

Results displayed in Table 3 showed that main effects of Weight, Time, Conc. and Temp. Sorp., squared effect of Weight*Weight, interaction effects of Weight*Time, Weight*Conc., Weight*Temp. Sorp. and Conc.*Temp. Sorp. were significant. The coefficient of determination $\left(\mathrm{R}^{2}\right)$ value of the model is 0.9358 indicating that the experimental data can be predicted well by the model.

Table 3. Statistical regression coefficients forMBremovel efficiency (\%) in coded units

\begin{tabular}{ccccc}
\hline Term & Coef & SE Coef & T-Value & P-Value \\
\hline Constant & 99.923 & 6.0371 & 16.552 & 0 \\
Weight & 17.8933 & 3.72058 & 4.809 & 0 \\
Time & 0.0777 & 0.02602 & 2.988 & 0.005 \\
Conc. & -0.2138 & 0.02588 & -8.26 & 0 \\
Temp. Sorp. & -0.036 & 0.08186 & -0.439 & 0.663 \\
Weight*Weight & -7.1018 & 0.90184 & -7.875 & 0 \\
Weight*Time & -0.0282 & 0.01243 & -2.268 & 0.029 \\
Weight*Conc. & 0.093 & 0.00746 & 12.468 & 0
\end{tabular}




$$
\begin{array}{lllll}
\text { Weight*Temp. Sorp. } & 0.067 & 0.02712 & 2.47 & 0.018 \\
\text { Conc.*Temp. Sorp. } & -0.001 & 0.00039 & -2.535 & 0.015
\end{array}
$$

Table 4. ANOVA results for the quadratic model

\begin{tabular}{cccccc}
\hline Source & DF & Seq SS & Adj MS & F & P \\
\hline Regression & 9 & 21262.6 & 2362.51 & 63.13 & 0 \\
Linear & 4 & 12464 & 1175.88 & 31.42 & 0 \\
Square & 1 & 2320.5 & 2320.54 & 62.01 & 0 \\
Interaction & 4 & 6478.1 & 1619.52 & 43.28 & 0 \\
Residual Error & 39 & 1459.4 & 37.42 & & \\
Lack-of-Fit & 15 & 824.4 & 54.96 & 2.08 & 0.053 \\
Pure Error & 24 & 634.9 & 26.46 & & \\
Total & 48 & 22722 & & & \\
\hline
\end{tabular}

The results of analysis of variance (ANOVA) is presented in Table 4. From the regression, low P-value $(<0.05)$ and large F-value (63.13) implied that the model was accurate. The non-significant value of lack of fit $(\mathrm{P}>0.05)$ also supports the accuracy of the model. In addition, high coefficient of determination $\mathrm{R}^{2}(0.9358)$ is adequate to describe the relationship between the response and variables. As it can have been observed, the values of $\mathrm{R}^{2}(0.9358)$ and $\mathrm{R}^{2}$ (adj) $(0.9209)$ of the model are close to each other which confirm the accuracy of the model. This denotes that $93.58 \%$ of the sample variation can be described by the independent variables.

\subsection{Main Effects}

Fig. 1 presents the main effect plot of all independent variables on the removal of MB dye molecules, which is the response $(\mathrm{R})$ of this study with the grand mean of $89.58 \%$. The effect of changing treatment temperature on sorption, while keeping the other parameters constant is illustrated in Fig. 1(a). The removal increased from $87.74 \%$ to $98.16 \%$ using T450 and then decreased to $84.97 \%$ when T800 was applied, showing that T450 sludge has the highest removal efficiency. Adsorption of methylene blue by kaolinite has been documented by [12] Based on our previous report [13], kaolinite was found in both raw and thermally treated alum sludge, but kaolinite in the sludge decreased remarkably when thermal treatment of sludge was conducted at $800^{\circ} \mathrm{C}$. Thus, removal efficiency of MB decreased when T800 was used. To investigate the effect of $\mathrm{pH}$ on $\mathrm{MB}$ uptake, sorption experiments were performed at different $\mathrm{pHs}$ in the range of 2.0-10.0, as shown in Fig. 1(b). The $\mathrm{pH}$ of MB solution was 
adjusted using $0.2 \mathrm{M}$ of $\mathrm{HCl}$ or $0.1 \mathrm{M}$ of $\mathrm{NaOH}$ solutions which introduced $\mathrm{H}^{+}$and $\mathrm{OH}^{-}$ions into the solutionsrespectively. The MB removal efficiency remarkably increased from $86.36 \%$ at $\mathrm{pH} 2$ to $98.17 \%$ at $\mathrm{pH} 6.0$ and then decreased to $86.36 \%$ at $\mathrm{pH} 10$. Similar result was documented by [14]. Lower removal efficiency at $\mathrm{pH} 2$ might due to the presence of higher amount of $\mathrm{H}^{+}$ions in the medium compared to that at $\mathrm{pH}$, which caused higher competition between $\mathrm{H}^{+}$ions with the $\mathrm{S}^{+}$from $\mathrm{MB}$ dye molecules for the sorption sites. Similar explanation was also documented by numerous researcher [10, 15-17]. However, the reason for lower removal efficiency at higher $\mathrm{pH}$ i.e. $\mathrm{pH} 10$ is different from the above explanation. Introduction of $\mathrm{OH}^{-}$ions into the $\mathrm{MB}$ solution, caused competitions between $\mathrm{OH}^{-}$ions and $\mathrm{Cl}^{-}$ (from MB molecules) for the sorption sites, thus leading to decrease in the sorption sites for MB molecules, consequently lower removal efficiency at $\mathrm{pH} 10$. Similar explanation was reported by [16].

The removal of MB as a function of sorbent dosage was evaluated at dosage between 0.1 and 3.0 g. as shown in Fig. 1(c). As it can be seen, the percentage removal increased drastically with the increase of sorbent dosage from 0.1 to $1.55 \mathrm{~g}$ could be attributed to higher surface area of sludge and a greater number binding sites are available. However, when highest sorbent dosage $(3.0 \mathrm{~g})$ was used, there was a little change in percentage removal. Similar result has been documented by [18] using montmorillonite clay to remove MB. According to [19], the sorbents may overlap each other which might prevent some of the active sites reached by the MB molecules. Thus, this may explain the observation at the highest dosage.

The percentage of MB dye removal varied with the varying contact period of sorption as depicted in Fig. 1(d). It can be seen that the percentage of MB dye removal increases rapidly with contact period and thereafter, the percentage removal decreased gradually. For example, the percentage removal increased from 86.38 to $98.16 \%$ when contact period increased from 60 to $120 \mathrm{~min}$. But, the percentage removal decreased from 98.16 to $86.33 \%$ when the contact period increased from 120 to $180 \mathrm{~min}$. Similar trend was found by [20]. According to [19], MB molecules have sufficient time for the adsorption when long contact period is provided. However, aggregation of dye molecules might occur when longer contact period is applied.This might cause difficulties in diffusion of MB molecules to the adsorbent. As a result, percentage removal decreased when longer contact period (180 min) was used. In contrast, lower percentage removal at contact period of $60 \mathrm{~min}$ might due to less sufficient time for MB dye molecules to adsorb onto the active sites.

Besides that, there was significantly change of percentage removal in the effect of initial 
concentration of MB dye, thus, the initial concentration of MB dye is one of the important factor in sorption of MB dye onto sludge sorbent. As concentration of MB dye increases from 50 to $150 \mathrm{mg} / \mathrm{L}$, the percentage removal increases slightly from 97.20 to $98.18 \%$ but decreases drastically $(75.50 \%$ ) as the initial concentration increased to $250 \mathrm{mg} / \mathrm{L}$ (Fig. 1(e)). Increase in MB removal with initial concentration can be caused by increase of MB which are available for more sorption but lower sorption at $250 \mathrm{mg} / \mathrm{L}$, as the sorption sites was saturated with MB molecules. The initial concentration provides the necessary driving force which this force overcome the resistance to the mass transfer of MB dye between solid and aqueous phase, therefore the interaction between dye molecules and sorbent enhanced and the sorption uptake increased [20]. Although driving force existed, high initial MB dye concentration may cause overload of the dye molecules. At $250 \mathrm{mg} / \mathrm{L}$, the active sites on the sorbent could be occupied completely and the higher amount of dye molecule remained in the solution which caused lowest percentage removal of MB molecules.

To study the effect of temperature of sorption on MB dye sorption by drinking water treatment sludge, the experiments were performed at temperatures of $25,52.5$ and $80{ }^{\circ} \mathrm{C}$. It is evident that the percentage removal increased rapidly as sorption temperature increased from 25 to $52.5{ }^{\circ} \mathrm{C}$, but the percentage removal decreased remarkably as sorption temperature increased from 52.5 to $80{ }^{\circ} \mathrm{C}$ (Fig. 1(f)). The increase of percentage removal implies not only the temperature has a significant effect on the sorption, but also the sorption of $\mathrm{MB}$ is an endothermic process. Some researcher has reported similar findings [10, 21]. Higher percentage removal at $65{ }^{\circ} \mathrm{C}$ compared to $25{ }^{\circ} \mathrm{C}$ might due to the mobility of the molecule dye increases [21]. However, in [10] documented that the rate of diffusion of the dye molecules across the external boundary layer and the internal pores of the sorbents particle increases when temperature increased due to the decrease in the viscosity of the solution. This might explain lower removal when temperature increased from 60 to $80{ }^{\circ} \mathrm{C}$ as more MB molecules diffuse from the sorbent. 


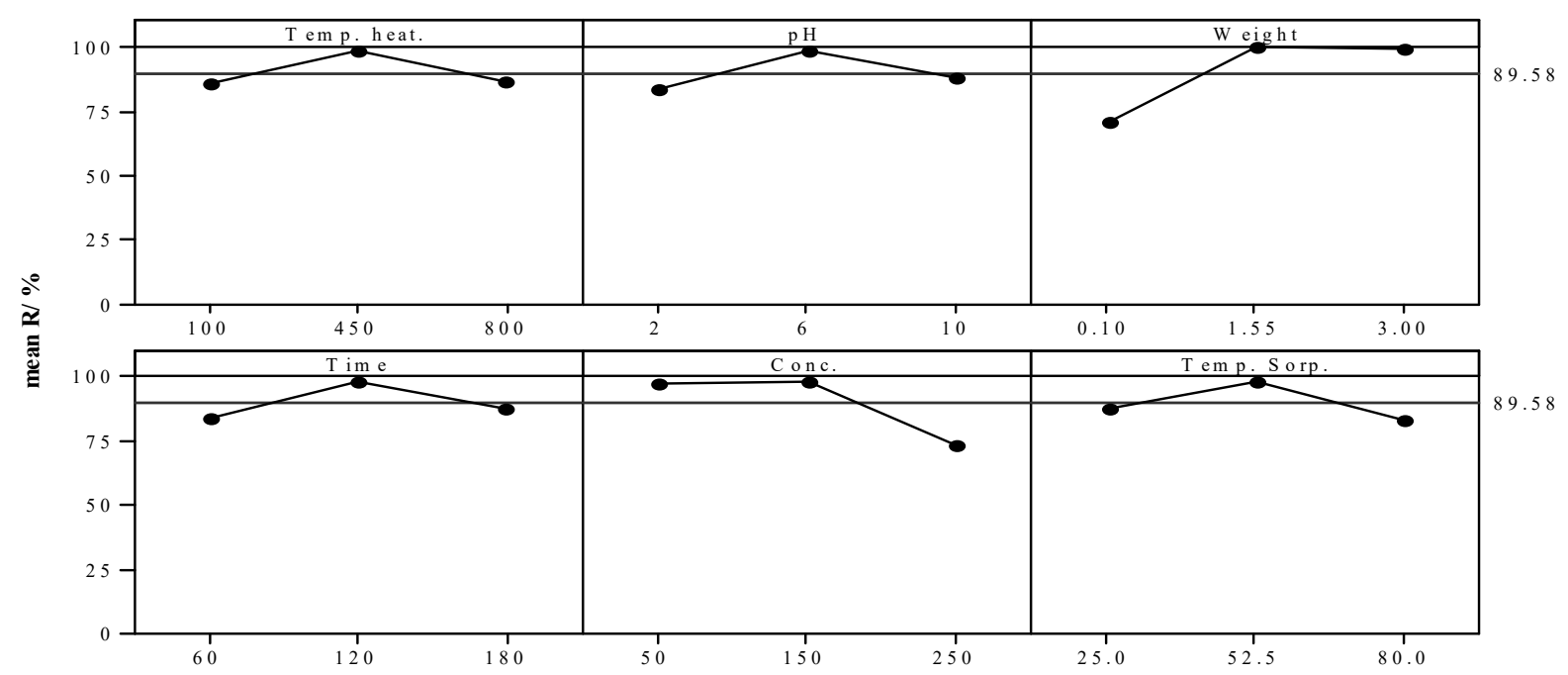

Fig.1. Effect of important parameters on the removal of MB dye molecules

\subsection{Response Contour Plot}

Fig. 2 illustrates the three-dimensional relationship between sorbent dosage and initial concentration was constructed for MB removal at constants $\mathrm{pH}(6)$, contact period (120 min), sorption temperature $\left(52.5^{\circ} \mathrm{C}\right)$ and treatment temperature $\left(450{ }^{\circ} \mathrm{C}\right)$. The interaction between both parameters were highly significant compared to other significant interaction effect as the MB removal increased from 95.00 to $110 \%$ at initial concentration of $50 \mathrm{mg} / \mathrm{L}$ when dosage of sorbent increased from 0.1 to $3.0 \mathrm{~g}$. The percentage removal for MB decreased from 95.00 to $45.00 \%$ dosage of sorbent at 0.1 gas initial concentration increased from 50 to $250 \mathrm{mg} / \mathrm{L}$. Consequently, with appropriate sorbent dosage $(1.55 \mathrm{~g})$ and initial concentration $(150 \mathrm{mg} / \mathrm{L})$, the optimum removal of $100 \%$ can be obtained as indicated by the peak of the plot. A good agreement was found when comparing the optimum value with that obtained by optimizing the regression model (Equation (3)).

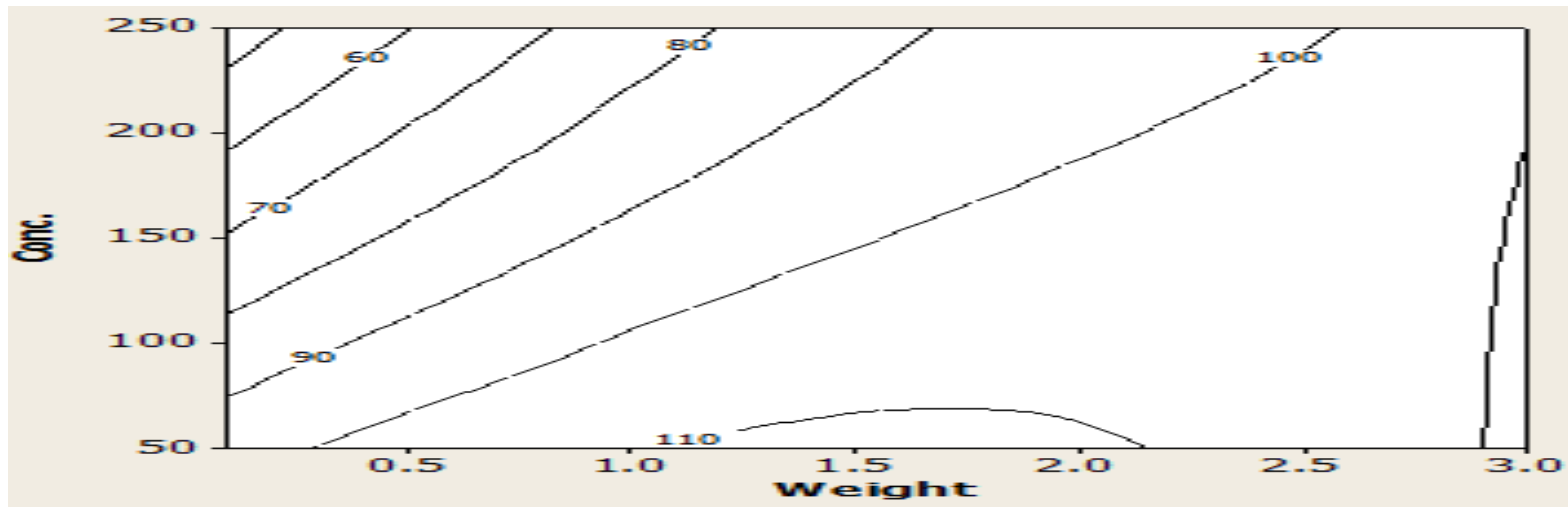

Fig.2. Response contour plot of percentage removal versus the effect of variables of initial concentration and dosage of sorbent 


\subsection{Optimization by Response Surface Optimizer}

The optimum conditions to achieve $99.94 \%$ removal of MB dye with 0.999 of composite desirability were predicted using response surface optimizer analysis and the results are depicted in Fig. 3. The results showed that the optimum conditions were suggested as: $1.55 \mathrm{~g}$ of sorbent dosage, $150 \mathrm{mg} / \mathrm{L}$ of initial dye concentration, treatment temperature of $450{ }^{\circ} \mathrm{C}, \mathrm{pH}$ 6 of $\mathrm{MB}$ solution, $120 \mathrm{~min}$ of contact and $52.5{ }^{\circ} \mathrm{C}$ of sorption temperature. Sorption experiments were conducted in 4 replications at these suggested optimum conditions and the removal percentages were 100, 99.99, 100 and $99.99 \%$ with the mean removal percentage of $100 \%$ which was close to the prediction removal of $99.94 \%$. Thus, the experimental results were in good agreement with the predicted values. It can be said that the model can predict the percentage removal accurately.

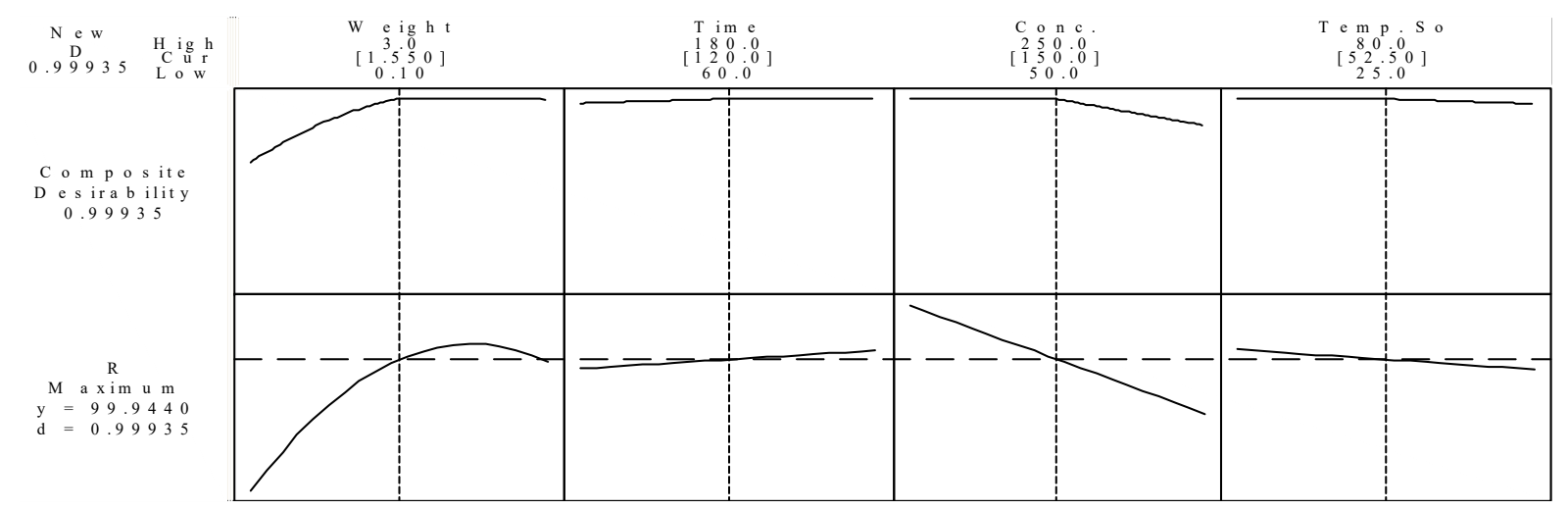

Fig.3. Response surface optimizer of MB dye removal using drinking water sludge

\section{CONCLUSION}

In this study, the sorption efficiency of drinking water treatment sludge was examined using MB dye solution. The effects of temperature of treatment, $\mathrm{pH}$ of solution, dosage of sorbent, initial dye concentration, contact period and temperature of sorption were investigated using ANOVA and the sorption conditions were optimized using RSM. The significance main effects were Weight, Time, Conc. and Temp. Sorp., squared effect of Weight*Weight, interaction effects of Weight*Time, Weight*Conc., Weight*Temp. Sorp., and Conc.*Temp. Sorp.. The optimum temperature of treatment, $\mathrm{pH}$ of solution, sorbent dosage, initial dye concentration, contact period and temperature of sorption were $450{ }^{\circ} \mathrm{C}, 6,1.55 \mathrm{~g}, 150 \mathrm{mg} / \mathrm{L}$, $120 \mathrm{~min}$ and $52.5{ }^{\circ} \mathrm{C}$ respectively for removal of $100 \%$ of MB removal using drinking water treatment sludge. It can be concluded that drinking water treatment sludge is effective in removing MB dye from the aqueous solution. Model prediction was in good agreement with the experimental data as indicated by high coefficient of determination $\left(\mathrm{R}^{2}\right)$ of 0.9358 . 


\section{ACKNOWLEDGMENTS}

The authors gratefully acknowledge supporting this study by University PertahananNasional Malaysia

\section{REFERENCES}

[1]Abdel-Ghani N T, El-Chaghaby G A, Helal F S. Individual and competitive adsorption of phenol and nickel onto multiwalled carbon nanotubes. Journal of Advanced Research, 2015, $6(3): 405-415$

[2] Albadarin A B, Mangwandi C. Mechanisms of Alizarin Red S and Methylene blue biosorption onto olive stone by-product: Isotherm study in single and binary systems. Journal of Environmental Management, 2015, 164:86-93

[3] Sarioglu M, Atay U A. Removal of Methylene blue by using biosolid. Global NEST Journal,2006, 8(2):113-120

[4] Yagub M T, Sen T K, Afroze S, Ang H M. Dye and its removal from aqueous solution by adsorption: A review. Advances in Colloid and Interface Science, 2014, 209:172-184

[5] Ataei-Germi T, Nematollahzadeh A. Bimodal porous silica microspheres decorated with polydopamine nano-particles for the adsorption of methylene blue in fixed-bed columns. Journal of Colloid and Interface Science, 2016, 470:172-182

[6] Dahri M K, Kooh M R, Lim L B. Application of Casuarina equisetifolia needle for the removal of methylene blue and malachite green dyes from aqueous solution. Alexandria Engineering Journal, 2015, 54(4):1253-1263

[7] Mohammed N, Grishkewich N, Waeijen H A, Berry R M, Tam K C. Continuous flow dsorption of Methylene blue by cellulose nanocrystal-alginate hydrogel beads in fixed bed columns. Carbohydrate Polymers, 2016, 136:1194-1202

[8] Isik M, Sponza D T. A batch study for assessing the inhibition effect of Direct Yellow 12 in a mixed methonogenic culture. Process Biochemistry, 2005, 40(3):1053-1062

[9] Kargi F, Ozmihci S. Biosorption performance of powdered ctivated sludge for removal of different dyestuffs. Enzyme and Microbial Tchnology, 2004, 35(2):267-271

[10 ]Agarwal S, Tyagi I, Gupta V K, Ghasemi N, Shahivand M, Ghasemi M. Kinetics, equilibrium studies and thermodynamics of methylene blue adsorption on Ephedra strobilacea sawdust and modified using phosphoric acid and zinc chloride. Journal of Molecular Liquids, 2016, 218:208-218 
[11] Otero M, Rozada F, Calvo L F, Garcia A I, Moran A. Kinetic and equilibrium modeling of methylene blue removal from aqueous solution by adsorbent materials produced from sewage sludges. Biochemical Engineering Journal, 2003, 15(1):59-68

[12] Krishnan K A, Ajmal K, Faisal A K, Liji T M. Kinetic and isotherm modeling of methylene blue adsorption onto kaolinite clay at the solid-liquid interface. Separation Science and Technology, 2015, 50(8):1147-1157

[13] Soleha M Y, Ong K K, Wan MdZin W Y, Mansor A, Anwar F, Azowa I N, Shafiq S A S M, Aisyah A S N, Aidy A, Ku Zarina K A, Teoh C C. Characterization of raw and thermally treated alum sludge. Key Engineering Materials, 2016, 701:138-142

[14] Liu C C, Li Y S, Chen Y M, Li H H, Wang M K. Removal of methylene blue using wine-processing waste sludge. Water Science and Technology, 2012, 65(12):2191-2199

[15] Fan S, Tang J, Wang Y, Li H, Zhang H, Tang J, Wang Z, Li X. Biochar prepared from co-pyrolysis of municipal sewage sludge and tea waste for the adsorption of methylene blue from aqueous solutions: Kinetics, isotherm, thermodynamic and mechanism. Journal of Molecular Liquids, 2016, 220:432-441

[16] Dashamiri S, Ghaedi M, Dashtian K, Rahimi M R, Goudarzi A, Jannesar R. Ultrasonic enhancement of the simultaneous removal of quaternary toxic organic dyes by $\mathrm{CuO}$ nanoparticles loaded on activated carbon: Central composite design, kinetic and isotherm study. Ultrasonics Sonochemistry, 2016, 31:546-557

[17] Asfaram A, Ghaedi M, Yousefi F, Dastkhoon M. Experimental design and modeling of ultrasound assisted simultaneous adsorption of cationic dyes onto $\mathrm{ZnS}$ : Mn-NPs-AC from binary mixture. Ultrasonics Sonochemistry, 2016, 33:77-89

[18] Almeida C A P, Debacher N A, Downs A J, Cottet L, Mello C A D. Removal of methylene blue from colored effluents by adsorption on montmorillonite clay. Journal of Colloid and Interface Science, 2009, 332(1):46-53

[19] Dutta S, Bhattacharyya A, Ganguly A, Gupta S, Basu S. Application of response surface methodology for preparation of low-cost adsorbent from citrus fruit peel and for removal of methylene blue. Desalination, 2011, 275(1):26-36

[20] Subramaniam R, Ponnusamy S K. Novel adsorbent from agricultural waste (cashew NUT shell) for methylene blue dye removal: Optimization by response surface methodology. Water Resources and Industry, 2015, 11:64-70

[21] Ghasemi M, Mashhadi S, Asif M, Tyagi I, Agarwal S, Gupta V K. Microwave-assisted synthesis of tetraethylenepentamine functionalized activated carbon with high adsorption 
capacity for Malachite green dye. Journal Molecular Liquid, 2016, 213:317-325

How to cite this article:

Yusuff S M, Ong K K, Yunus W M Z W, Fitrianto A, Ahmad M B. Removal of methylene blue from aqueous solutions using alum sludge: sorption optimization by response surface methodology. J. Fundam. Appl. Sci., 2017, 9(3S), 532-545 